\title{
Creating Robust Superamphiphobic Coatings for Both Hard and Soft Materials
}

Received 00th January 20xx, Accepted 00th January 20xx

DOI: $10.1039 / \times 0 x \times 00000 x$

www.rsc.org/

\author{
Faze Chen ${ }^{a}$, Jinlong Song ${ }^{a *}$, Yao Lu ${ }^{b}$, Shuai Huang ${ }^{a}$, Xin Liu ${ }^{a}$, Jing Sun ${ }^{a}$, Claire J. Carmalt ${ }^{b}$, Ivan P. \\ Parkin $^{\mathrm{b}}$, Wenji Xü
}

\begin{abstract}
Most superhydrophobic surfaces lose their water-repellency when either contaminated by oily liquids or by being mechanically damaged. Superamphiphobic surfaces are ones that repel both oil and water. However, to date such surfaces are hampered by being mechanically weak. Robust superamphiphobic surfaces with highly water and oil repellent properties are desired for a wide range of environments. Reported herein is a superamphiphobic coatings fabricated by a facile deposition method and followed by a low surface energy materials modification. These coatings can be applied on both hard and soft materials to repel water, glycerol and peanut-oil droplets. Falling sand abrasion and UV irradiation were used to test the surface robustness and durability. A multi-cycle stretch/release test was developed to characterize the robustness of the self-cleaning soft materials. A coated rubber-bond retained both water and oil repellency even after 50 stretch/release cycles. These tests show that the superamphiphobic coatings have remarkable mechanical durability and UV resistance and can be readily applied to a wide variety of materials to form self-cleaning surfaces that are extremely robust even under intense strains.
\end{abstract}

\section{Introduction}

Nature offers many examples that have inspired researchers to minimize solid-liquid interfacial interactions to fabricate liquid repellent materials, such as the leaves of Lotus and Rice plants ${ }^{1-}$ 3 , the Namib Desert Beetle ${ }^{4}$, water strider legs ${ }^{5}$, etc. ${ }^{6-8}$. In the last two decades, superhydrophobic surfaces with water contact angles $>150^{\circ}$ and sliding angles $<10^{\circ}$ have attracted much attention due to their various applications in anti-icing ${ }^{9-12}$, self-cleaning ${ }^{13-15}$, oil/water separation ${ }^{14,16-18}$, corrosion resistance ${ }^{19-21}$, surfaces patterning $22-24$ and lab-on-chip systems ${ }^{25-27}$. However, most superhydrophobic surfaces are easily contaminated by oil ${ }^{28}$, which greatly limits their practical applications in many environments. Compared with superhydrophobic surfaces, superamphiphobic surfaces - which repel both water and oil, are more likely to be used for water/oil proofing in an oily environment ${ }^{29,30}$. The repulsion of oil by a surface is much more difficult to achieve than water repellency, because most oils have low surface tension making it easier for oils to penetrate and wet a surface. In order to repel liquids with a wide range of surfaces tensions, surface micro-morphologies are required to be specially designed such as a re-entrant

a. Key Laboratory for Precision and Non-Traditional Machining Technology of Ministry of Education, Dalian University of Technology, Dalian 116024, China. Email address:wenjixu@dlut.edu.cn (Prof.W. J.Xu), songjinlong@dlut.edu.cn (Dr. J. L. Song).

b. Materials Chemistry Research Centre, Department of Chemistry, University College London, 20 Gordon Street, London, WC1H OAJ, UK

Electronic Supplementary Information (ESI) available: [details of any supplementary information available should be included here]. See DOI: 10.1039/x0xx00000x structure ${ }^{28,30-37}$. Tuteja et al. ${ }^{30-32}$ employed electrospun fibers to demonstrate that design of re-entrant structures on an initiallyoleophilic flat surface allows the construction of superamphiphobic surfaces with extreme non-wetting properties to water and various organic liquids. Zhao et al. ${ }^{38}$ fabricated super-toner and ink-repellent superoleophobic surface by photolithographic technique followed by surface modification. Song et $a .^{34}$ constructed re-entrant micro/nanometer-scale rough structures on Al substrates by electrochemical etching and immersion in $\left[\mathrm{Ag}\left(\mathrm{NH}_{3}\right)_{2}\right]^{+}$solution. The resulting surfaces showed superior oil repellency capacity with a peanut-oil contact angle of $160.0 \pm 2^{\circ}$. Liu et al..$^{39}$ used a combinational method, including plasma etching, physical deposition and chemical etching, to construct a specific doubly re-entrant structure that enables very low liquid-solid contact fraction, and renders the surface super-repellent.

Among the aforementioned methods, superamphiphobic surfaces have only been prepared on one of several substrates, such as glass ${ }^{35,36}$, metal ${ }^{34,40}$ and fabrics ${ }^{32,41}$. Few reports have shown a general method to make superamphiphobic coatings both on hard (metal and glass) and soft/flexible (scouring pad, sponge, filter paper and rubber) substrates. Coating methods, such as dip-coating and spray-deposition, are other widely employed methods in the fabrication of liquid repellent surfaces ${ }^{15,41-44}$. Coatings can be easily applied onto various substrates, and the coated surfaces can also be easily repaired once the surfaces are damaged. However, the existing methods to fabricate superamphiphobic coatings are somewhat complicated. In addition, most of the liquid repellent coatings 

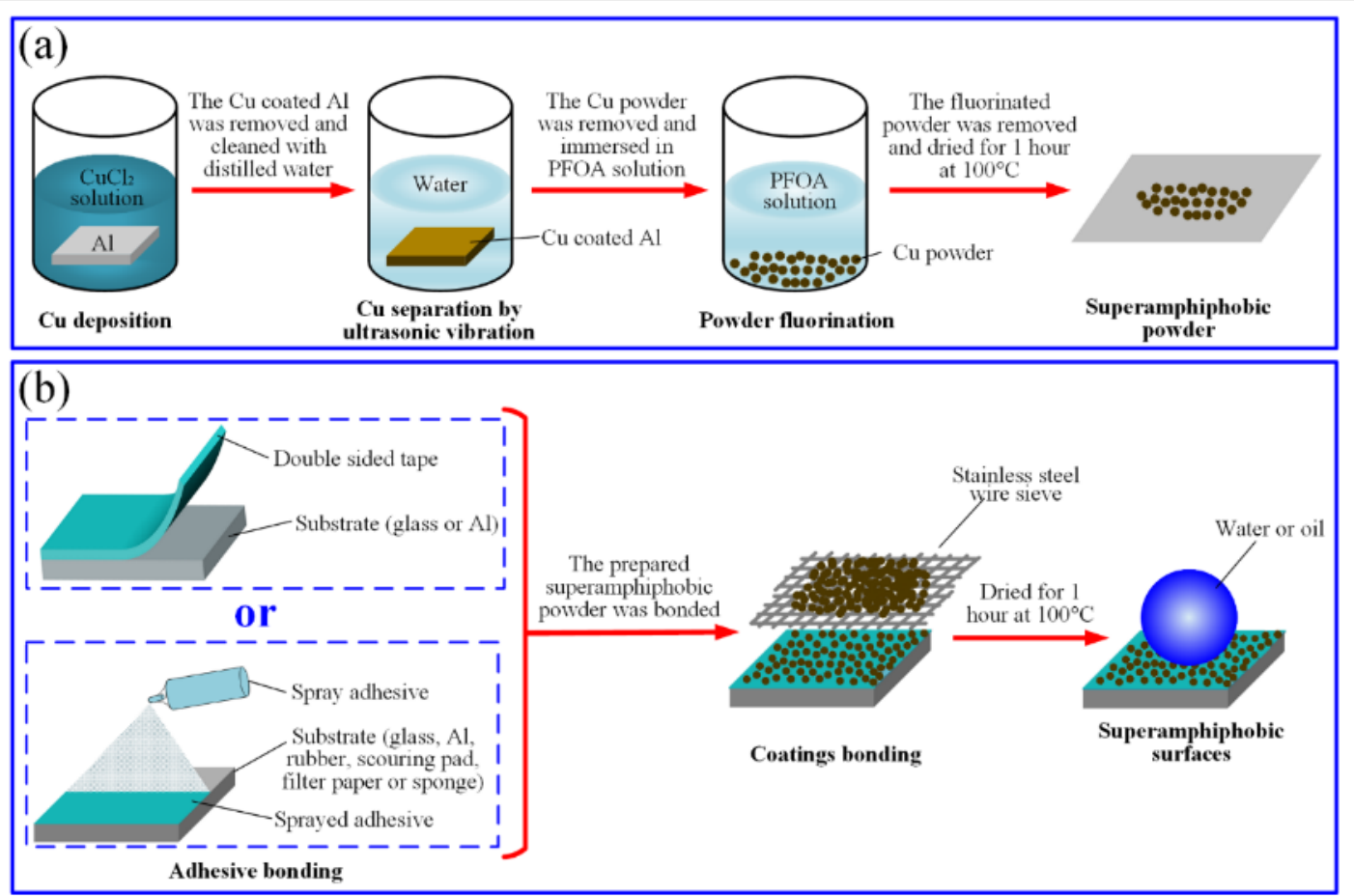

Fig. 1 Illustration of (a) the fabrication of the superamphiphobic powder and (b) the bonding of the powder onto various substrates.

are obtained from pre-made sol, resins or suspension ${ }^{41,45-48}$, the storage stability of these pre-made mixtures could be a potential problem. Thus, a facial method to fabricate superamphiphobic coatings that is easy-to-preserve and has long-term-stability is urgently needed.

Robustness and durability are important issues in nonwetting surfaces fabrication because the morphologies (e.g. micro/nano hierarchical roughness, re-entrant structures etc.) on those surfaces are very mechanically weak and sometimes being removed by simply touching with a tissue ${ }^{49}$. Deng et al. ${ }^{43,44}$ obtained robust super-liquid repellent coatings and investigated the mechanical resistance by sand abrasion tests. Sand grains (100 to $300 \mathrm{~mm}$ in diameter) impinged the surfaces from a height of 10 to $\sim 40 \mathrm{~cm}$. UV irradiation is also widely used to evaluate the durability of non-wetting surfaces ${ }^{48,50}$. Recently, it was found that commercial adhesives were effective to bond superhydrophobic coatings on both hard and soft materials with highly improved robustness ${ }^{15}$, which points to be a new way to improve the robustness of super-liquid repellent coatings.

In this paper, we firstly used a facile chemical deposition and low surface energy modification to fabricate superamphiphobic powder. The powder was simply coated on hard, soft and stretchable/flexible materials via spray adhesives or double sided tape to make superamphiphobic surfaces. The coated surfaces showed remarkable robustness and durability under falling sand abrasion and UV exposure tests. We also developed a new multi-cycle stretch-release test to characterize the robustness of self-cleaning soft flexible materials. The treated rubber retained superamphiphobicity even after 50 cycles of stretch-release tests and it is believed that these coatings can be readily applied to the circumstances where self-cleaning is required under intense strains.

\section{Experimental}

\subsection{Materials}

Al plates (purity $\geqslant 99.9 \%$ ) were purchased from the Dalian Aluminum Material Manufacturer (China). Perfluorooctanoic acid [PFOA, $\mathrm{CF}_{3}\left(\mathrm{CF}_{2}\right)_{6} \mathrm{COOH}$, purity $\geqslant 96 \%$ ] was purchased from Sigma-Aldrich (USA). Analytical-grade glycerol and $\mathrm{CuCl}_{2}$ were purchased from Tianjin Kermel Chemical Reagent Co. (China). Peanut-oil was purchased from Luhua Co. (China). Glass slide and soft porous materials (scouring pad, sponge, filter paper and rubber) were purchased from Wal-Mart Stores in Dalian, China. Commercial adhesive, including the double sided tape (3M Scotch Brand Tape, core series 4-1000) and the spray adhesive (3M 77\#), were purchased from $3 \mathrm{M}$ China. The surface tensions of water, glycerol and peanut-oil are about $72.1 \mathrm{mN} / \mathrm{m}$, $63.6 \mathrm{mN} / \mathrm{m}$ and $34.5 \mathrm{mN} / \mathrm{m}$, respectively ${ }^{29,43}$. In the experiment, glycerol and peanut-oil were respectively dyed blue and yellow using oil blue and oil yellow to aid visualization, and this did not change the behavior of the droplets on the surfaces.

\subsection{Fabrication of superamphiphobic coatings on both hard and soft materials}

A simple chemical deposition and low surface energy modification was used to fabricate the superamphiphobic 

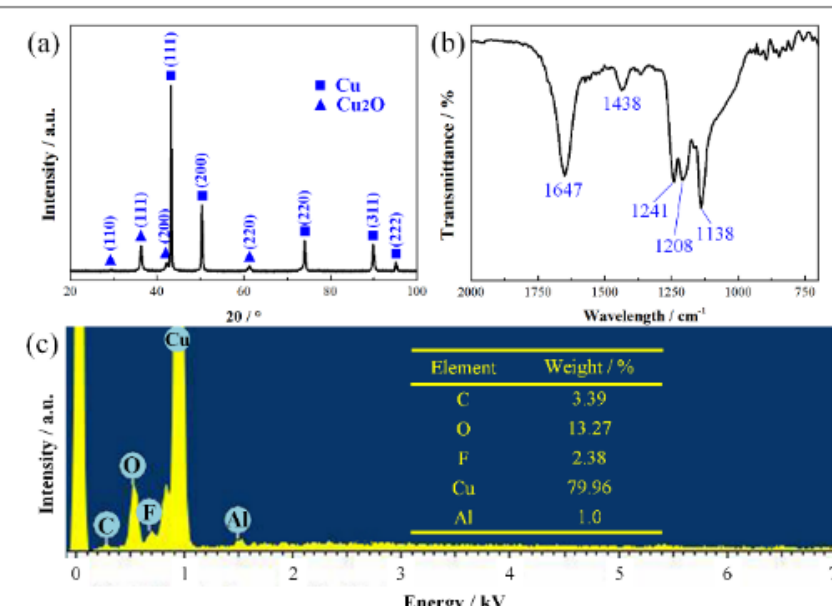

Fig. 2 (a) XRD patterns, (b) FTIR and (c) EDS spectra of the PFOA coated $\mathrm{Cu} / \mathrm{Cu}_{2} \mathrm{O}$ powder.

coatings as shown schematically in Fig. 1(a). Al plates were polished mechanically using $1000 \#$ and $2000 \#$ abrasive paper and then ultrasonically cleaned in sequence in alcohol and deionized water solvents. After drying in air, the Al plates were immersed in the $1 \mathrm{~mol} / \mathrm{L}$ aqueous $\mathrm{CuCl}_{2}$ solution at ambient temperature for $30 \mathrm{~s}$ to deposit a layer of $\mathrm{Cu}$ via a chemical substitution reaction. After immersion, the Cu-coated Al plates were thoroughly rinsed with deionized water to eliminate any residual salts and then the plates were ultrasonically cleaned with deionized water for $30 \mathrm{~s}$ to partially remove and refine the deposited dark red $\mathrm{Cu}$. The separated $\mathrm{Cu}$ powder was then immersed in the $0.015 \mathrm{~mol} / \mathrm{L}$ aqueous PFOA solution for $2 \mathrm{~min}$ to coat the powder and reduce its surface energy. Finally, the PFOA coated Cu powder was dried at $100^{\circ} \mathrm{C}$ for 1 hour to obtain a superamphiphobic powder. Notably the obtained powder can be easily preserved in an air environment for more than 1 year without obvious loss of superamphiphobicity.

The superamphiphobic powder can be combined with spray adhesives or double sided tapes and easily coated on hard (Al and glass slide) and soft (rubber, scouring pad, sponge and filter paper) materials. After drying in air, the coated surfaces were noted to be superamphiphobic, as shown in Fig. 1(b).

\subsection{Sample characterization}

The crystal structures of the superamphiphobic powder were examined by X-ray diffractometer system (XRD-6000, Japan). The $X$-ray source was a $\mathrm{Cu} K \alpha$ radiation $(\lambda=0.15418 \mathrm{~nm})$, which was operated at $40 \mathrm{kV}$ and $40 \mathrm{~mA}$ with a scanning rate of $2 \theta=$ $0.026 \mathrm{deg} / \mathrm{min}$ and a range of $20-100^{\circ}$. The chemical compositions of the powder was characterized by energydispersive X-ray spectroscope (EDS, INCA Energy, Oxford Instruments), and Fourier transform infrared spectrophotometer (FTIR, JASCO, Japan). The surface morphologies of the coated samples were observed by scanning electron microscope (SEM, JSM-6360LV, Japan). Contact angles (CAs) and roll-off angles (RAs) were measured by an optical
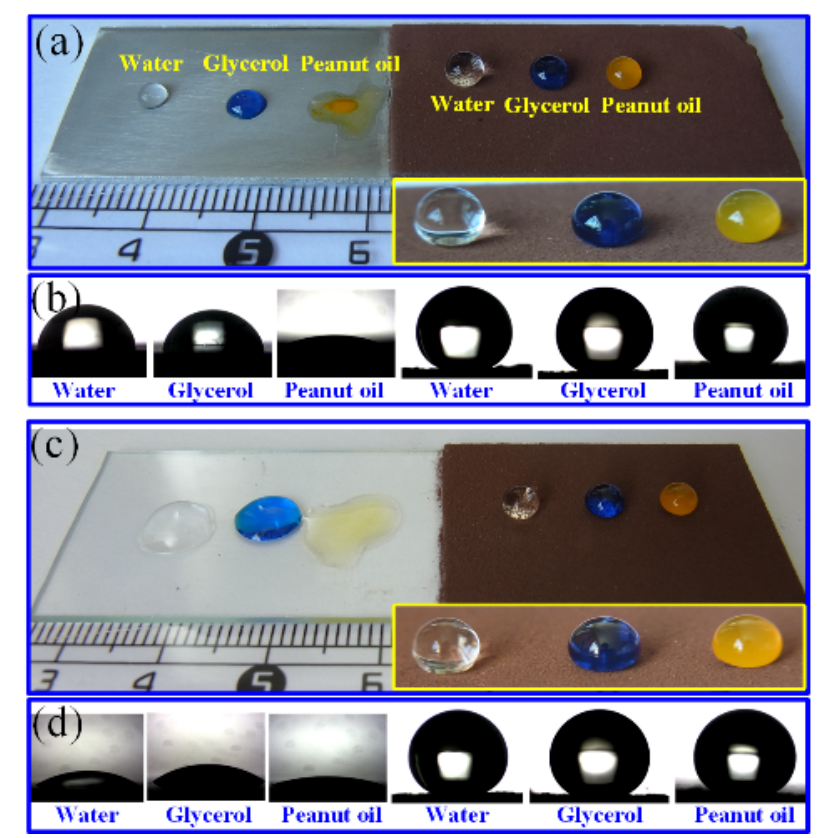

Fig. 3 Water, glycerol and peanut-oil droplets on the host substrates and the superamphiphobic coated substrates: (a) and (b) Al; (c) and (d): glass slide.

contact angle meter (Krüss, DSA100, Germany) at room temperature by dropping droplets of $5 \mu \mathrm{L}$ onto the coated surfaces and the average of five measurements obtained at different positions was used as the final CA/RA.

\subsection{Surface robustness tests}

Falling sand abrasion and UV irradiation tests were carried out to test the robustness of the superamphiphobic coatings on hard materials, and coated glass substrates were used as examples. $150 \mathrm{~g}$ of sand grains (300 to $800 \mu \mathrm{m}$ in diameter) impinged the tilted surfaces $\left(45^{\circ}\right.$ ) from different heights $h$ ( 0 to $\sim 100 \mathrm{~cm}$, the corresponding velocities before impingement were 0 to $\sim 4.47 \mathrm{~m} / \mathrm{s}$, see Supporting Information, Section S1). CAs and RAs were measured after each abrasion test. To evaluate the UV resistance, the CAs and RAs of the superamphiphobic coatings after exposure to UV irradiation ( $365 \mathrm{~nm}, 32 \mathrm{~W}$ ) for 24 hours were measured. A coated rubberbond $(\sim 3.0 \mathrm{~cm})$ was stretched to $\sim 6.0 \mathrm{~cm}$ and then released (this process was defined as one cycle) to demonstrate the robustness.

\section{Results and discussion}

Fig. 2(a) shows the XRD patterns of the superamphiphobic powder. Five diffraction peaks at $2 \theta=43.28^{\circ}, 50.38^{\circ}, 74.12^{\circ}$, $89.90^{\circ}$, and $95.11^{\circ}$, respectively, correspond to the characteristic peaks of the $\mathrm{Cu}(111), \mathrm{Cu}(200), \mathrm{Cu}(220), \mathrm{Cu}(311)$, and $\mathrm{Cu}(222)$ planes of the face-centered cubic $\mathrm{Cu}$ crystals (JCPDS Card No. 04-0836). Reflections at $2 \theta=29.48^{\circ}, 36.34^{\circ}$, $42.39^{\circ}$ and $61.43^{\circ}$ matched the characteristic peaks of the 
Table I. Contact angles (CA) and Rolling off angle (RA) values of the uncoated and coated hard materials.

\begin{tabular}{lllllll}
\hline & \multicolumn{2}{c}{ Water } & \multicolumn{2}{c}{ Glycerol } & \multicolumn{2}{c}{ Peanut-oil } \\
\cline { 2 - 7 } & \multicolumn{1}{c}{ CA } & \multicolumn{1}{c}{ RA } & \multicolumn{1}{c}{ CA } & RA & CA & RA \\
\hline Uncoated Al & $79.6 \pm 1.5^{\circ}$ & None & $71.9 \pm 1.7^{\circ}$ & None & $18.7 \pm 1.5^{\circ}$ & None \\
Coated Al & $158.8 \pm 1.2^{\circ}$ & $2.5 \pm 0.7^{\circ}$ & $156.5 \pm 1.1^{\circ}$ & $3.7 \pm 0.6^{\circ}$ & $152.9 \pm 1.2^{\circ}$ & $6.9 \pm 1.1^{\circ}$ \\
Uncoated glass slide & $32.6 \pm 0.8^{\circ}$ & None & $33.6 \pm 1.4^{\circ}$ & None & $18.7 \pm 0.3^{\circ}$ & None \\
Coated glass slide & $158.2 \pm 2.1^{\circ}$ & $2.1 \pm 1.3^{\circ}$ & $155.4 \pm 1.6^{\circ}$ & $4.3 \pm 1.2^{\circ}$ & $152.1 \pm 2.1^{\circ}$ & $6.8 \pm 0.8^{\circ}$ \\
\hline
\end{tabular}
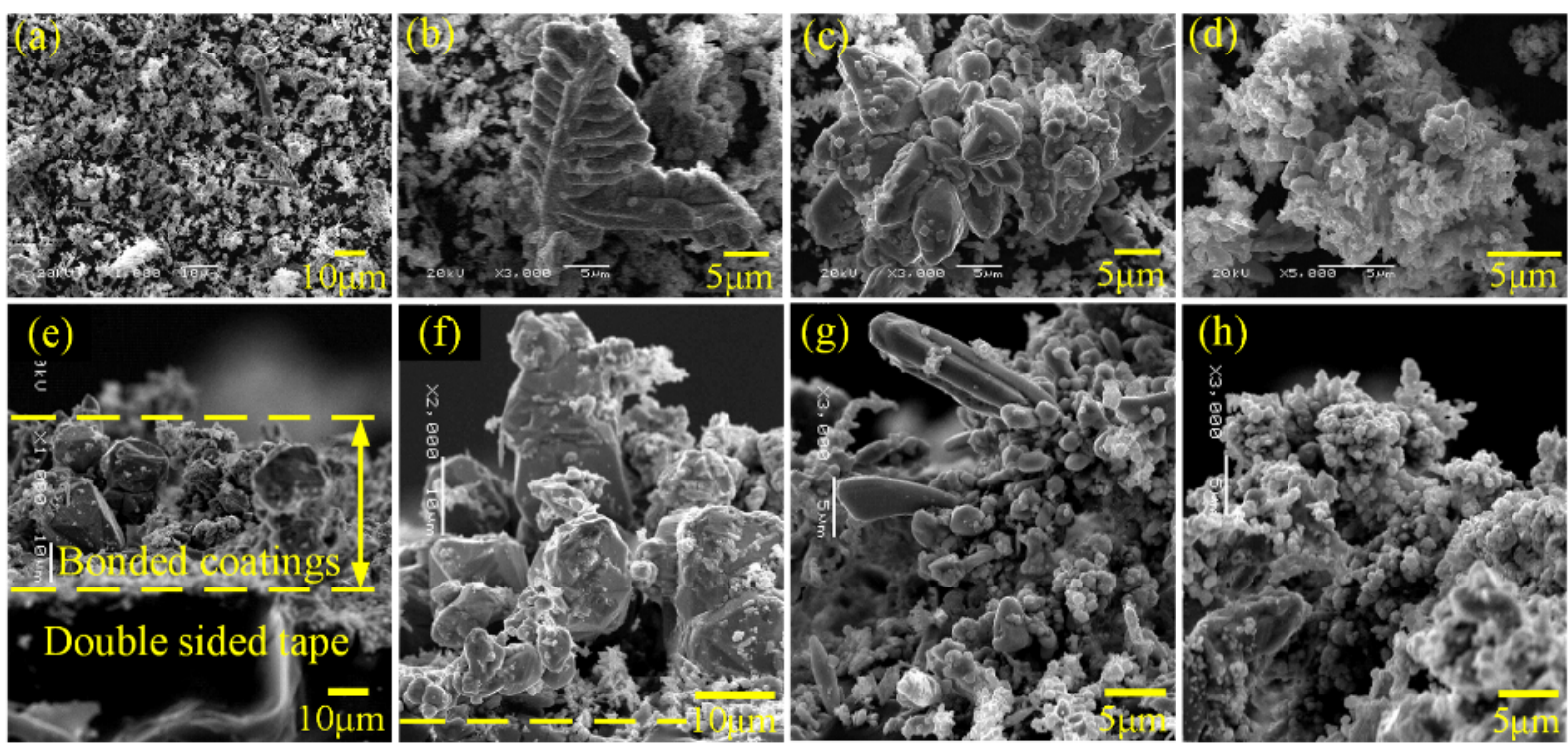

Fig. 4 (a)-(d) Top-view and (e)-(h) cross-sectional-view SEM images of the superamphiphobic coatings on glass slide.

$\mathrm{Cu}_{2} \mathrm{O}(110), \mathrm{Cu}_{2} \mathrm{O}(111), \mathrm{Cu}_{2} \mathrm{O}(200)$ and $\mathrm{Cu}_{2} \mathrm{O}(220)$ planes, respectively (JCPDS Card No. 05-0667). The formation of $\mathrm{Cu}$ occurs through a simple redox reaction as shown in Equation (1), where the aluminium acts as a reducing agent to take $\mathrm{Cu}^{2+}$. Part of the produced $\mathrm{Cu}$ reacted with oxygen to form $\mathrm{Cu}_{2} \mathrm{O}$ [Equation (2)]. Fig. 2(b) shows the FTIR spectra of the superamphiphobic coatings. Bands at 1647 and $1438 \mathrm{~cm}^{-1}$ were respectively attributed to the asymmetrical stretching vibrations and symmetrical stretching vibrations of - $\mathrm{COO}$ groups of the perfluorooctanoic acid (PFOA) molecules ${ }^{51}$. The presence of the bands at 1138,1208 and $1241 \mathrm{~cm}^{-1}$ were attributed to the $-\mathrm{CF}$ stretching vibrations of $-\mathrm{CF}_{2}$ and $-\mathrm{CF}_{3}$ groups ${ }^{51,52}$. The results of $X R D$ and FTIR show that the main compositions of the superamphiphobic powder were $\mathrm{Cu}$ and $\mathrm{Cu}_{2} \mathrm{O}$ cores covered with $-\mathrm{CF}_{2}$ and $-\mathrm{CF}_{3}$ groups which have a low surface energy and can effectively reduce the surface energy of the highly textured $\mathrm{Cu}$ and $\mathrm{Cu}_{2} \mathrm{O}$ powders. The EDS spectrum shown in Fig. 2(c) also demonstrated the elements of the superamphiphobic powder with $\mathrm{Cu}$ and $\mathrm{O}$ from $\mathrm{Cu}$ and $\mathrm{Cu}_{2} \mathrm{O}$, the elements $\mathrm{C}$ and $\mathrm{F}$ were from PFOA and small amounts of Al was from the Al plate used during the aforementioned reductions [Fig. 1(a)].

$$
\begin{gathered}
2 \mathrm{Al}+3 \mathrm{Cu}^{2+} \rightarrow 3 \mathrm{Cu}+2 \mathrm{Al}^{3+} \\
4 \mathrm{Cu}+\mathrm{O}_{2} \rightarrow 2 \mathrm{Cu}_{2} \mathrm{O}
\end{gathered}
$$

The prepared superamphiphobic powder can be bonded onto hard materials via dropping the powder through a sieve on to either double sided tape or a surface pre-treated with a spray adhesive. Fig. 3 shows water, glycerol and peanut-oil droplets on the original and the bonded Al [Fig. 3(a) and (b)] and glass slide substrates [Fig. 3(c) and (d)], respectively. The superamphiphobic coatings presented here was bonded by double sided tape. The contact angles (CAs) and rolling off angles (RAs) of the samples are list in Table I. Water, glycerol and peanut-oil droplets spread onto the as-received Al and glass slide substrates, exhibiting hydrophilicity and lipophilicity. For the coated surfaces, the testing liquid droplets remained as near spheres and could easily roll off from the surfaces (see Supporting Information, Videos S1 and S2), showing excellent superhydrophobicity and superoleophobicity. The coated regions exhibited water, glycerol and peanut oil CAs of approximately $158^{\circ}, 156^{\circ}$ and $153^{\circ}$, respectively, irrespective of the substrate.

Special surface micro structures (i.e. re-entrant structures) are essential for the superamphiphobicity. Here we used SEM to detect the micro structures endowed from the prepared superamphiphobic coatings. Fig. 4(a)-(d) show the top-view SEM images of the superamphiphobic coatings with different magnifications. Many irregularly shaped features with sizes ranging from several hundred nanometers to dozens of micrometers were uniformly bonded on the surface [Fig. 4(a)] and formed a rough morphology. Top-view SEM images in high magnification presented the structured morphologies with 


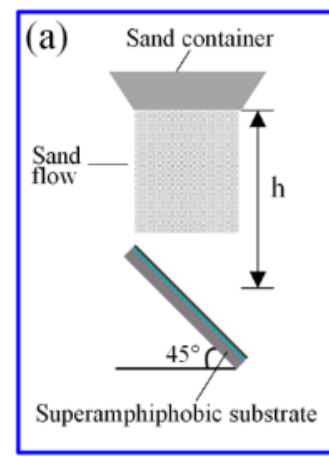

(d)

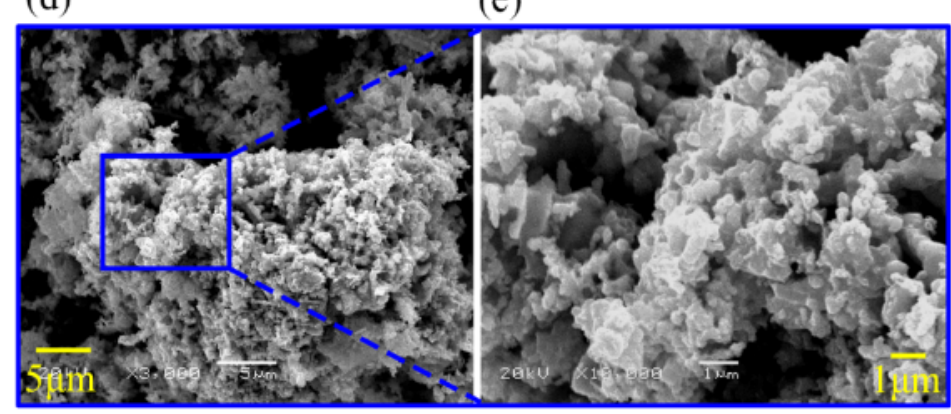

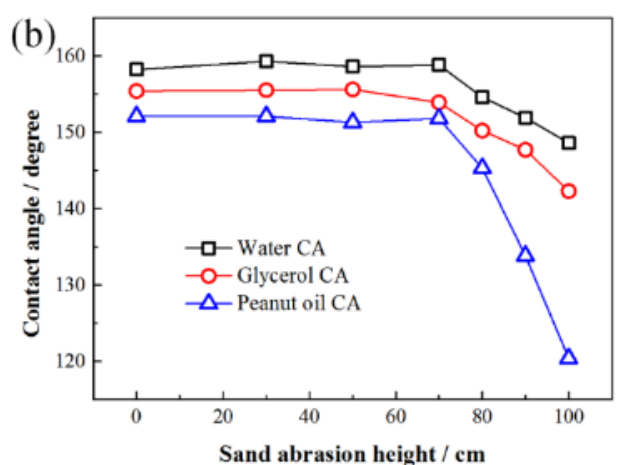
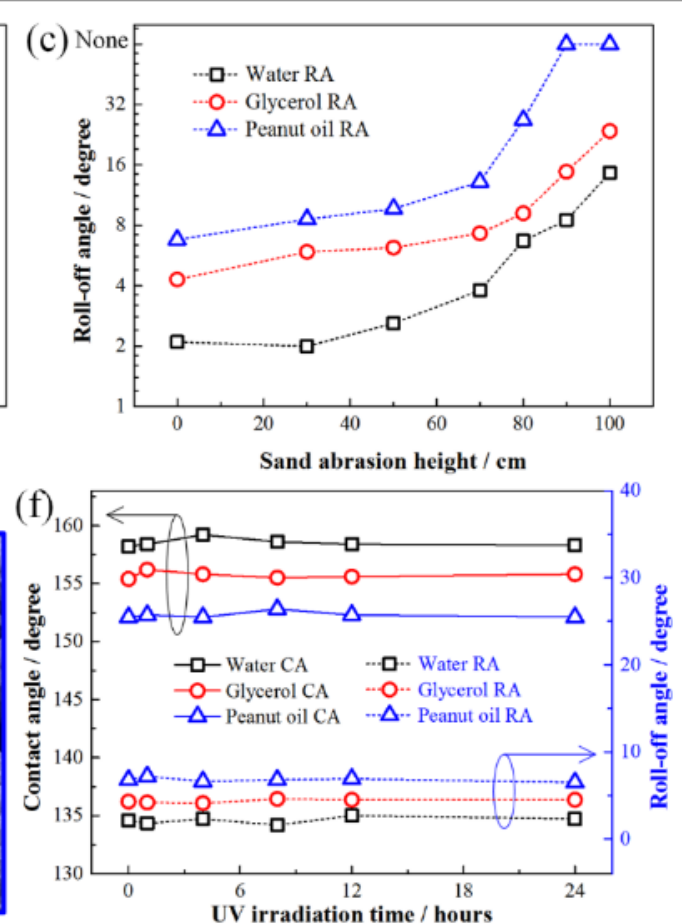

Fig. 5 Mechanical resistance and durability quantified by sand abrasion and UV irradiation. (a) Schematic drawing of a sand abrasion experiment; [(b) and (c)] Plot of water, glycerol and peanut-oil CAs and RAs after each abrasion tests for different heights of sand abrasion; [(d) and (e)] SEM images of a micro structure after sand impingement $(h=50 \mathrm{~cm})$ with different magnification; (f) Water, glycerol and peanut-oil CAs and RAs of the coatings after UV irradiation ( $365 \mathrm{~nm}, 32 \mathrm{~W}$ ) for different times.

micro-nano sized features that in some locations resembled leaf shapes [Fig. 4(b)], protrusions [Fig. 4(c)] and coralline-shaped [Fig. 4(d)] structures. Fig. 4(e)-(h) show the cross-sectionalview SEM images of the superamphiphobic coatings. The coated superamphiphobic layer was about $45 \mu \mathrm{m}$ thick, wherein some irregularly shaped micro-sized large particles were observed, as shown in Fig.4(e). The cross-sectional-view SEM images in higher magnification in Fig. 4(f)-(h) respectively displayed three typical structures: blocky, dendritic and coralline-shaped structures. These structures are randomly agglomerated and were covered with numerous micro/nano-particles, creating micron- or submicron-sized valleys, protrusions, pits and pores. These surface textures further created re-entrant geometries at multiple scales. When exposing liquid droplets contact with the coated surfaces, the highly roughened surface structures decreased the solid-liquid interfacial interactions and the reentrant geometries capable of trapping air at the interface construct a composite solid-liquid-air interface, a wetting behavior in the Cassie-Baxter state ${ }^{53}$ was thereafter formed. Therefore, water, glycerol and peanut-oil droplets were supported by these surface structures as nearly spherical shapes and easily rolled off from the coated superamphiphobic surfaces.

The coated surfaces maintained their superamphiphobicity after being placed in a laboratory air environment at room temperature for more than a year earlier. To further demonstrate the robustness and durability of the bonded superamphiphobic coatings, falling sand abrasion and UV irradiation tests were performed. Fig. 5(a) shows the schematic drawing of the falling sand abrasion tests. Fig. 5(b) and (c) respectively depict the CAs and RAs of water, glycerol and peanut-oil droplets on the coatings after sand abrasion from 0 to $\sim 100 \mathrm{~cm}$ height. It clearly shows that when $h \leq 70 \mathrm{~cm}$, though the coatings suffered from intense sand abrasion for as long as $2 \mathrm{~min}$, the CAs and RAs changed little and the coatings maintained their superamphiphobicity. Video $\mathrm{S} 3$ shows a falling sand abrasion from a height of $50 \mathrm{~cm}$ (impact velocity $3.16 \mathrm{~m} / \mathrm{s}$ and impact energy $\sim 5.65 \times 10^{-7}$ to $1.07 \times 10^{-5} \mathrm{~J}$, see Supporting Information, Section S1), and Fig. 5(d) and (e) present the corresponding SEM images. The coatings were not sufficiently robust to completely resist sand impact and some microstructures were destroyed [Fig. 5(d)]. However, zooming into the destroyed structures revealed almost unaltered corallineshaped structures, consisting of many pits and bumps [Fig. 5(e)]. For $h$ larger than $70 \mathrm{~cm}$, the impact energy was high and the microstructures of the coatings were heavily damaged (see Supporting Information, Section S1 and Fig. S2), which resulted in the CAs of the testing liquid droplets decreased rapidly and the corresponding RAs increased, indicating that the superamphiphobicity was weakened [Fig. 5(b) and (c)]. Fig. 5(f) shows the water, glycerol and peanut-oil CAs and RAs of the samples under UV exposure for different times. It clearly shows that the CAs and RAs remained similar after UV irradiation for 


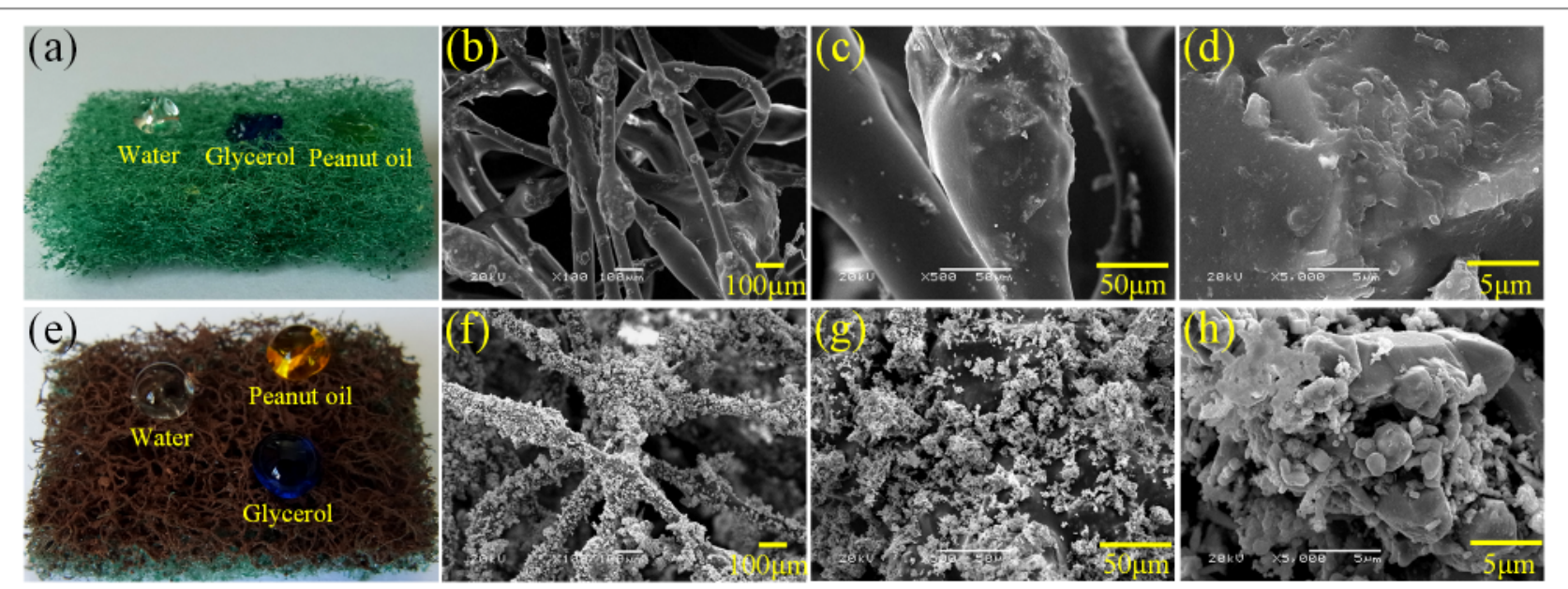

Fig. 6 Photograph of water, glycerol and peanut-oil droplets on (a) the original and (e) the coated scouring pad; SEM images of (b)(d) the original and ( $f)-(h)$ the coated scouring pad.

more than 24 hours, indicating that both surface morphology and chemistry changed little after UV irradiation.

The superamphiphobic coatings were also applied to soft porous substrates by spray adhesives. Fig. 6(a) shows water, glycerol and peanut-oil droplets on the original scouring pad. For the original scouring pad, fibers with diameter of $\sim 50 \mu \mathrm{m}$ intersected with each other and some radial expansion $(\sim 100 \mu \mathrm{m})$ along the fibers were observed. Some micro-sized dome-like features were randomly distributed on the fibers [Fig. 6(b)-(d)], generating a common hydrophobic but lipophilic wettability. Water droplet stayed on the surface as a hemisphere but glycerol and peanut-oil droplets totally penetrated the untreated scouring pad. However, the coated scouring pad exhibited good liquid repellency for water, glycerol and peanut-oil by keeping the droplets near spherical shape without any penetration or adhesion (though some of the droplets were trapped in the concave structures), as shown in Fig. 6(e). The SEM images of the coated scouring pad [Fig. 6(f)(h)] show that all the fibres were covered with superamphiphobic $\mathrm{Cu}$ and $\mathrm{Cu}_{2} \mathrm{O}$ particles, preventing the testing liquids adhered to the fibres or penetrated into the substrate through the porous macrostructures.

The original sponge is hydrophilic and lipophilic, and which can be wetted by both water and oils, exhibiting poor liquid repellent properties, as shown in Fig. 7(a). After being treated with the superamphiphobic coatings, the sponge held all the liquid droplets as quasi-spheral shapes on the uppermost layer of the sponge [Fig. 7(e)] and there was no adhesion apparent as the droplets rolled off the inclined surface (see Supporting Information, Video S4). The SEM images show that the framework surfaces of the original sponge were very smooth [Fig. 7(b)-(d)]. However, after coatings, all the surfaces of the framework were highly textured and covered with superamphiphobic $\mathrm{Cu}$ and $\mathrm{Cu}_{2} \mathrm{O}$ particles, as shown in Fig. 7(f)(h).

Our coatings are also effective in converting the wetting behavior of extremely hydrophilic/oleophilic filter paper. Fig. 8(a) shows the reverse wettability between the uncoated

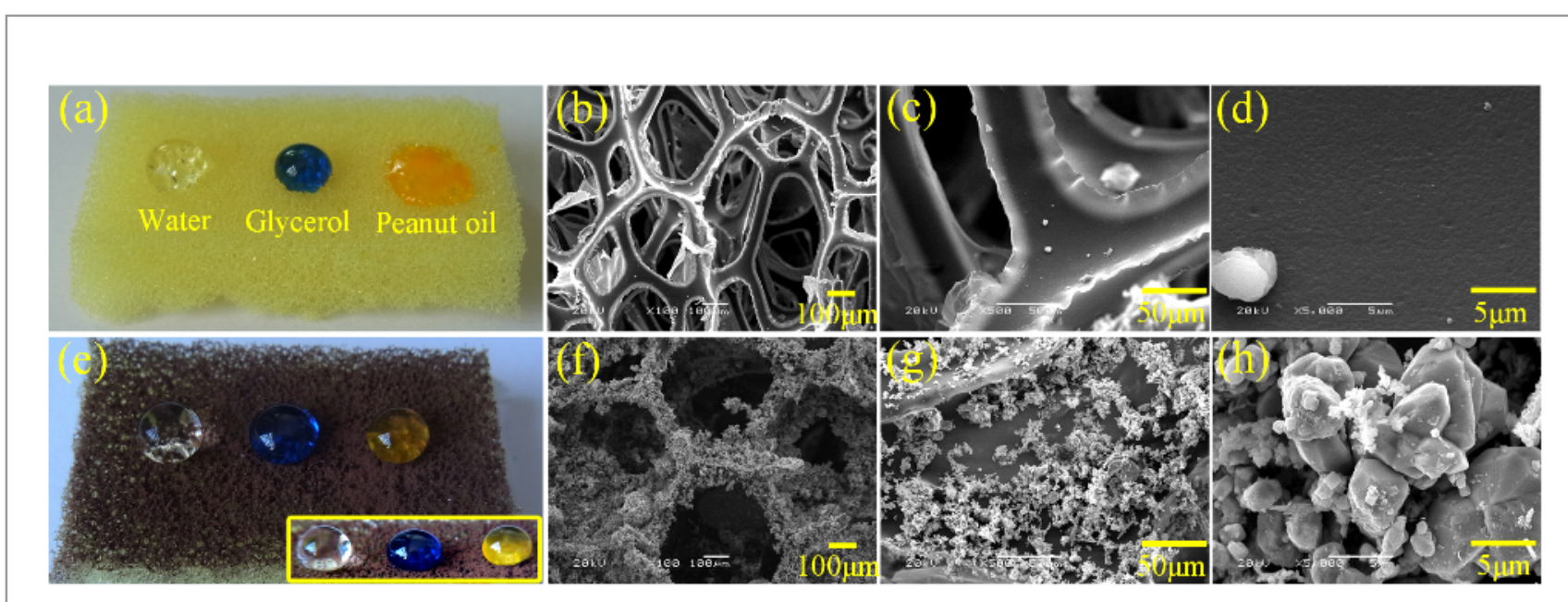

Fig. 7 Photograph of water, glycerol and peanut-oil droplets on (a) the original and (e) the coated sponge; SEM images of (b)-(d) the original and $(f)-(h)$ the coated sponge. 


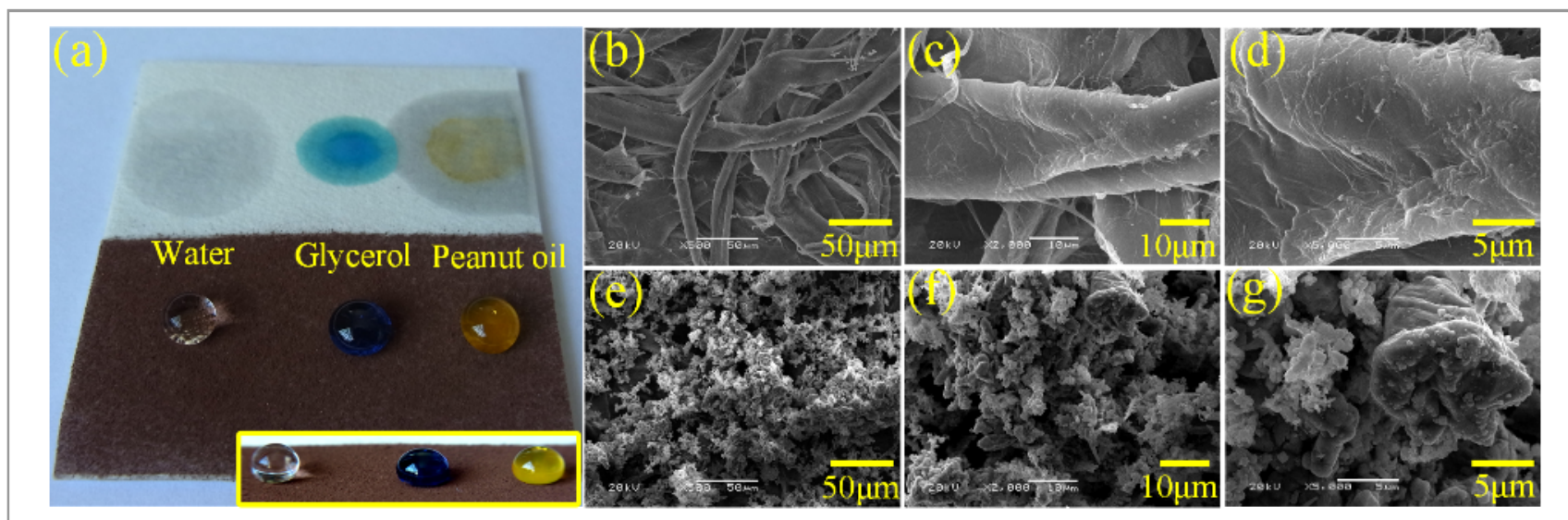

Fig. 8 Photograph of water, glycerol and peanut-oil droplets on (a) the original and (e) the coated filter paper; SEM images of (b)(d) the original and $(\mathrm{f})-(\mathrm{h})$ the coated filter paper.

and the coated regions of the filter paper. The uncoated region can be completely wetted by water, glycerol and peanut-oil droplets, indicating extremely hydrophilic/oleophilic properties, because of the existence of cavities [Fig. 8(b)] and abundant hydroxyl groups in filter paper structure ${ }^{54}$. In the magnified SEM images of uncoated filter paper [Fig. 8(c) and (d)], numerous longitudinal corrugations along the paper fiber with diameters of $\sim 25 \mu \mathrm{m}$ and a few micro-scale particles were observed. However, after coating, the paper fibers were almost all covered with superamphiphobic $\mathrm{Cu}$ and $\mathrm{Cu}_{2} \mathrm{O}$ particles [Fig. 8(e)-(g)]. The filter paper covered with the superamphiphobic coatings cannot be wetted by water or oils [Fig. 8(a)] and presented outstanding superamphiphobicity. The CAs of water, glycerol and peanut-oil were respectively $159.3 \pm 3.4^{\circ}, 156.9 \pm 3.6^{\circ}$ and $154.2 \pm 2.5^{\circ}$, and the droplets could also roll off from the coated surfaces easily (see Supporting Information, Video S5).

Creating oil repellent surfaces on stretchy substrates that work under liquid environments is an important and challenging work since the deformation of the stretchy substrates would "dilute" and even damage the surface structures. In order to show our superamphiphobic coatings are suitable to stretchy substrates, we used a piece of rubber $(3.0 \mathrm{~cm}$ in length) as the substrate and superamphiphobic coatings were bonded by sprayed adhesive. Fig. 9(a) and (c) show the photos of water, glycerol and peanut-oil droplets on the coated rubber before and after stretching, respectively. It clearly shows that the three liquid droplets on the surface were close to spherical and easily rolled off even after being stretched to double the original length of rubber (see Supporting Information, Video S6). Fig. 9(b) and (d) respectively shows the SEM images of the
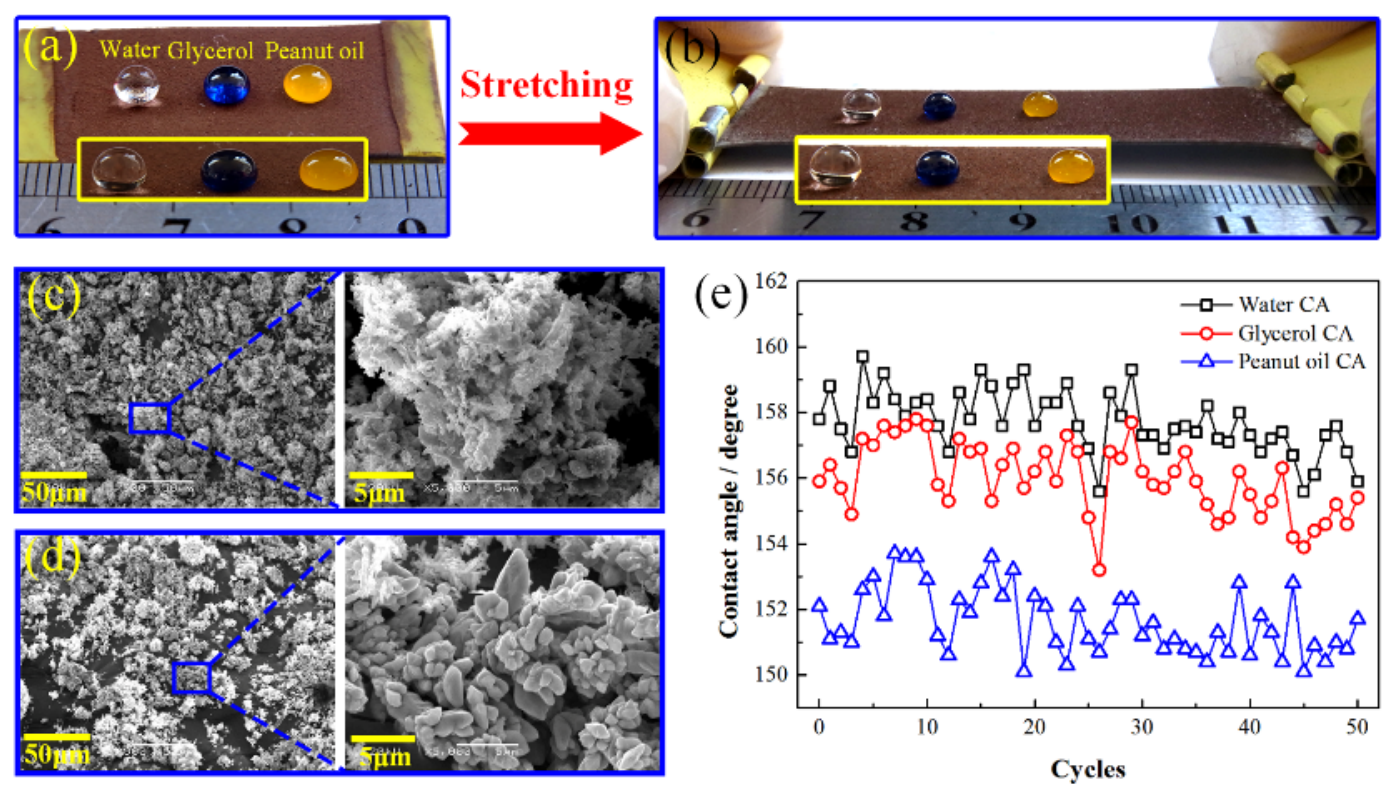

Fig. 9 Photograph of water, glycerol and peanut-oil droplets on coated rubber (a) before and (b) after stretching; SEM images of the coated rubber (c) before and (d) after stretching; (e) Plot of water, glycerol and peanut-oil contact angles after each stretch and release cycle. 
superamphiphobic coatings before and after stretching. Compared with Fig. 4, although the microstructures were distributed sparsely after being stretched by mechanical stress, the surface micro-morphologies did not change much, which enabled the coated surfaces to retain their superamphiphobicity. The water, glycerol and peanut-oil CAs during 50 cycles of stretching and releasing test remained above $150^{\circ}$, as shown in Fig. 9(e). Thus it was demonstrated that the superamphiphobicity was maintained even after stretching and releasing for more than 50 cycles (see Supporting Information, Video S6), which demonstrated the possibility to build robust superamphiphobic surfaces on stretchy substrates.

\section{Conclusions}

In summary, we reported a facile method to fabricate superamphiphobic coatings with CAs for different liquids (water, glycerol and peanut-oil) all in excess of $150^{\circ}$ and RAs lower than $10^{\circ}$. The superamphiphobic coatings were obtained by chemical deposition and subsequent surface coating with fluorination and could be easily coated on both hard (metal and glass) and soft materials (scouring pad, sponge, filter paper and rubber) via adhesives. Sand abrasion and UV irradiation tests were used to evaluate the robustness of the coatings, and the results indicated that the coatings have good mechanical resistance and durability. A multi-cycle stretch-release method was developed to test the robustness of self-cleaning soft flexible materials. The treated rubber surprisingly remained superamphiphobicity even after 50 cycles of stretch-release tests. These results demonstrate that the new coatings can be readily applied to a wide range of materials to produce extremely durable superamphiphobic coatings that maintain both oil and water repulsion even after intense UV-exposure, multiple stress-strain cycles and sand abrasion.

\section{Acknowledgements}

This work was financially supported by National Natural Science Foundation of China (NSFC, Grant No. 90923022), the Fundamental Research Funds for the Central Universities (DUT15RC(3)066) and an Innovation and Creativity Fund for Doctoral Students Granted by Science \& Technology Review (Grant No. KJDB2012010).

\section{References}

1 W. Dong, W. Jian-Nan, W. Si-Zhu, C. Qi-Dai, Z. Shuai, Z. Hao, S. Hong-Bo, and J. Lei, Adv. Funct. Mater., 2011, 21, 2927.

2 S. G. Lee, H. S. Lim, D. Y. Lee, D. Kwak, and K. Cho, Adv. Funct. Mater., 2013, 23, 547.

3 W. Barthlott and C. Neinhuis, Planta, 1997, 202, 1.

4 L. Zhai, M. C. Berg, F. C. Cebeci, Y. Kim, J. M. Milwid, M. F. Rubner, and R. E. Cohen, Nano Lett., 2006, 6, 1213.

$5 \quad$ X. Gao and L. Jiang, Nature, 2004, 432, 36.

6 F. Xia and L. Jiang, Adv. Mater., 2008, 20, 2842.
$7 \quad$ K. Liu and L. Jiang, Nano Today, 2011, 6, 155.

8 K. Liu and L. Jiang, ACS Nano, 2011, 5, 6786.

9 K. K. Varanasi, T. Deng, J. D. Smith, M. Hsu, and N. Bhate, Appl. Phys. Lett., 2010, 97, 234102.

10 X. Yao, Y. Song and L. Jiang, Adv. Mater., 2011, 23, 719.

11 P. Guo, Y. Zheng, M. Wen, C. Song, Y. Lin, and L. Jiang, Adv. Mater., 2012, 24, 2642.

12 L. B. Boinovich, A. M. Emelyanenko, V. K. Ivanov, and A. S. Pashinin, ACS Appl. Mater. Interfaces, 2013, 5, 2549.

13 Y. Chen, Y. Zhang, L. Shi, J. Li, Y. Xin, T. Yang, and Z. Guo, Appl. Phys. Lett., 2012, 101, 33701.

14 X. Zhang, Z. Li, K. Liu, and L. Jiang, Adv. Funct. Mater., 2013, 23, 2881.

15 Y. Lu, S. Sathasivam, J. Song, C. R. Crick, C. J. Carmalt, and I. P. Parkin, Science, 2015, 347, 1132.

16 J. Song, S. Huang, Y. Lu, X. Bu, J. E. Mates, A. Ghosh, R. Ganguly, C. J. Carmalt, I. P. Parkin, W. Xu, and C. M. Megaridis, ACS Appl. Mater. Interfaces, 2014, 6, 19858.

17 Y. Lu, S. Sathasivam, J. Song, F. Chen, W. Xu, C. J. Carmalt, and I. P. Parkin, J. Mater. Chem. A, 2014, 2, 11628.

18 C. Duan, T. Zhu, J. Guo, Z. Wang, X. Liu, H. Wang, X. Xu, Y. Jin, N. Zhao, and J. Xu, ACS Appl. Mater. Interfaces, 2015, 1415334719.

19 W. Xu, J. Song, J. Sun, Y. Lu, and Z. Yu, ACS Appl. Mater. Interfaces, 2011, 3, 4404.

20 Z. Wang, Q. Li, Z. She, F. Chen, and L. Li, J. Mater. Chem., 2012, 22, 4097.

21 K. C. Chang, H. I. Lu, C. W. Peng, M. C. Lai, S. C. Hsu, M. H. Hsu, Y. K. Tsai, C. H. Chang, W. I. Hung, Y. Wei, and J. M. Yeh, ACS Appl. Mater. Interfaces, 2013, 5, 1460.

22 P. Auad, E. Ueda and P. A. Levkin, ACS Appl. Mater. Interfaces, 2013, 5, 8053.

23 M. Toma, G. Loget and R. M. Corn, ACS Appl. Mater. Interfaces, 2014, 6, 11110.

24 F. Chen, W. Xu, Y. Lu, J. Song, S. Huang, L. Wang, I. P. Parkin, and X. Liu, Micro Nano Lett., 2015, 10, 105.

25 M. Elsharkawy, T. M. Schutzius and C. M. Megaridis, Lab Chip, 2014, 14, 1168.

26 A. Ghosh, R. Ganguly, T. M. Schutzius, and C. M. Megaridis, Lab Chip, 2014, 14, 1538.

27 F. Lapierre, M. Harnois, Y. Coffinier, R. Boukherroub, and V. Thomy, Lab Chip, 2014, 14, 3589.

28 H. Butt, C. Semprebon, P. Papadopoulos, D. Vollmer, M. Brinkmann, and M. Ciccotti, Soft Matter, 2012, 9, 418.

29 Y. Lu, J. Song, X. Liu, W. Xu, Y. Xing, and Z. Wei, ACS Sustainable Chem. Eng., 2013, 1, 102.

30 A. Tuteja, W. Choi, M. Ma, J. M. Mabry, S. A. Mazzella, G. C. Rutledge, G. H. McKinley, and R. E. Cohen, Science, 2007, 318, 1618.

31 A. Tuteja, W. Choi, G. H. McKinley, R. E. Cohen, and M. F. Rubner, Mrs Bull., 2008, 33, 752.

32 W. Choi, A. Tuteja, S. Chhatre, J. M. Mabry, R. E. Cohen, and G. H. McKinley, Adv. Mater., 2009, 21, 2190. 


\section{Journal Name}

33 Y. Liu, Y. Xiu, D. W. Hess, and C. P. Wong, Langmuir, 2010, 26, 8908.

34 J. Song, S. Huang, K. Hu, Y. Lu, X. Liu, and W. Xu, J. Mater. Chem. A, 2013, 1, 14783.

35 V. A. Ganesh, S. S. Dinachali, A. S. Nair, and S. Ramakrishna, ACS Appl. Mater. Interfaces, 2013, 5, 1527.

36 Z. Geng, J. He, L. Xu, and L. Yao, J. Mater. Chem. A, 2013, 1, 8721.

37 H. Bellanger, T. Darmanin, E. T. de Givenchy, and F. Guittard, Chem. Rev., 2014, 114, 2694.

38 H. Zhao and K. Law, ACS Appl. Mater. Interfaces, 2012, 4, 4288.

39 T. L. Liu and C. J. Kim, Science, 2014, 346, 1096.

40 J. Xi, L. Feng and L. Jiang, Appl. Phys. Lett., 2008, 92, 53102.

41 H. Zhou, H. Wang, H. Niu, A. Gestos, and T. Lin, Adv. Funct. Mater., 2013, 23, 1664.

42 L. Xiong, L. L. Kendrick, H. Heusser, J. C. Webb, B. J. Sparks, J. T. Goetz, W. Guo, C. M. Stafford, M. D. Blanton, S. Nazarenko, and D. L. Patton, ACS Appl. Mater. Interfaces, 2014, 6, 10763.

43 X. Deng, L. Mammen, H. J. Butt, and D. Vollmer, Science, 2012, $335,67$.

44 X. Deng, L. Mammen, Y. Zhao, P. Lellig, K. Müllen, C. Li, H. Butt, and D. Vollmer, Adv. Mater., 2011, 23, 2962.

45 T. M. Schutzius, I. S. Bayer, J. Qin, D. Waldroup, and C. M. Megaridis, ACS Appl. Mater. Interfaces, 2013, 5, 13419.

46 Z. Xu, Y. Zhao, H. Wang, X. Wang, and T. Lin, Angew. Chem. Int. Ed., 2015, 54, 4527.

47 S. G. Lee, D. S. Ham, D. Y. Lee, H. Bong, and K. Che, Langmuir, 2013, 29, 15051.

48 R. G. Karunakaran, C. Lu, Z. Zhang, and S. Yang, Langmuir, 2011, 27, 4594.

49 T. Verho, C. Bower, P. Andrew, S. Franssila, O. Ikkala, and R. H. A. Ras, Adv. Mater., 2011, 23, 673.

50 J. Zhang, B. Li, L. Wu, and A. Wang, Chem. Commun. (Camb), 2013, 49, 11509.

51 X. Xu, Z. Zhang and W. Liu, Colloids Surfaces A: Physicochem. Eng. Aspects, 2009, 341, 21.

52 X. Li, P. Zhang, L. Jin, T. Shao, Z. Li, and J. Cao, Environ. Sci. Technol., 2012, 46, 5528.

53 A. B. D. Cassie and S. Baxter, T. Faraday Soc., 1944, 40, 546.

54 X. Huang, X. Wen, J. Cheng, and Z. Yang, Appl. Surf. Sci., 2012, 258, 8739. 


\section{Graphical Abstract}

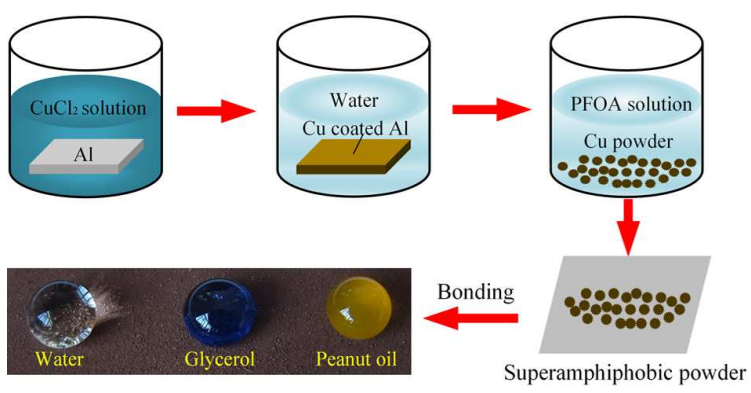




\section{Supporting Information for}

\section{Creating Robust Superamphiphobic Coatings for Both Hard and Soft Materials}

Faze Chen ${ }^{a}$, Jinlong Song ${ }^{a *}$, Yao Lu ${ }^{b}$, Shuai Huang ${ }^{a}$, Xin Liu ${ }^{a}$, Jing Sun ${ }^{a}$, Claire J. Carmalt ${ }^{b}$, Ivan P. Parkin ${ }^{b}$, Wenji $^{2}$ $\mathrm{Xu}^{\mathrm{a}^{*}}$

${ }^{a}$ Key Laboratory for Precision and Non-Traditional Machining Technology of Ministry of Education, Dalian University of Technology, Dalian 116024, China

b Materials Chemistry Research Centre, Department of Chemistry, University College London, 20 Gordon Street, London, WC1H OAJ, UK

\section{S1: Calculation of the impact energy of a sand grain}

Here, we regarded a sand grain as a sphere with a radius of $R$, so the mass of a sand grain, $m$, can be estimated as

$m=4 / 3 \pi R^{3} \rho$

where $\rho$ denotes the density of silica $\left(\rho \approx 2 \mathrm{~g} / \mathrm{cm}^{3}\right)$. The impact energy of a sand grain, $W$, can be determined by

$W=m g h=4 / 3 \pi R^{3} \rho g h$

where $g$ is the acceleration of gravity, and $h$ the height of the sand.

The impact velocity of a sand grain, $v$, can be obtained by $v=(2 h g)^{-1 / 2}$

In this work, the radius of the sand, $R$, was in the range of 300 to $800 \mu \mathrm{m}$, and the height of the sand, $h$, ranging from 0 to $\sim 100 \mathrm{~cm}$. Therefore, the impact energy, $W$, can be estimated as follows:

\begin{tabular}{|c|c|c|c|c|}
\hline$h(\mathrm{~cm})$ & 20 & 50 & 80 & 100 \\
\hline$v(\mathrm{~m} / \mathrm{s})$ & 2.0 & 3.16 & 4.0 & 4.47 \\
\hline$W(\mathrm{~J})$ & $2.27 \times 10^{-7}$ to $4.29 \times 10^{-6}$ & $5.65 \times 10^{-7}$ to $1.07 \times 10^{-5}$ & $9.05 \times 10^{-7}$ to $1.72 \times 10^{-5}$ & $1.13 \times 10^{-6}$ to $2.14 \times 10^{-5}$ \\
\hline
\end{tabular}

\footnotetext{
* Corresponding authors. Tel.: 86-411-84708422; Fax: 86-411-84708422. E-mail address: wenjixu@dlut.edu.cn (Prof. W. J. Xu), songjinlong@dlut.edu.cn (Dr. J. L. Song).
} 


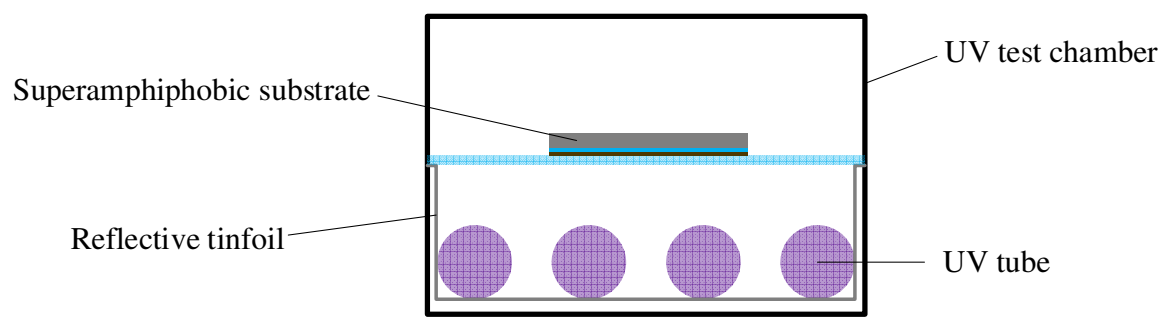

Fig. S1. Schematic diagram of UV irradiation of a coated glass slide substrate. The substrate was placed face-down to the UV light source $(365 \mathrm{~nm}, 32 \mathrm{~W})$ for different times, ranging from 0 to 24 hours.
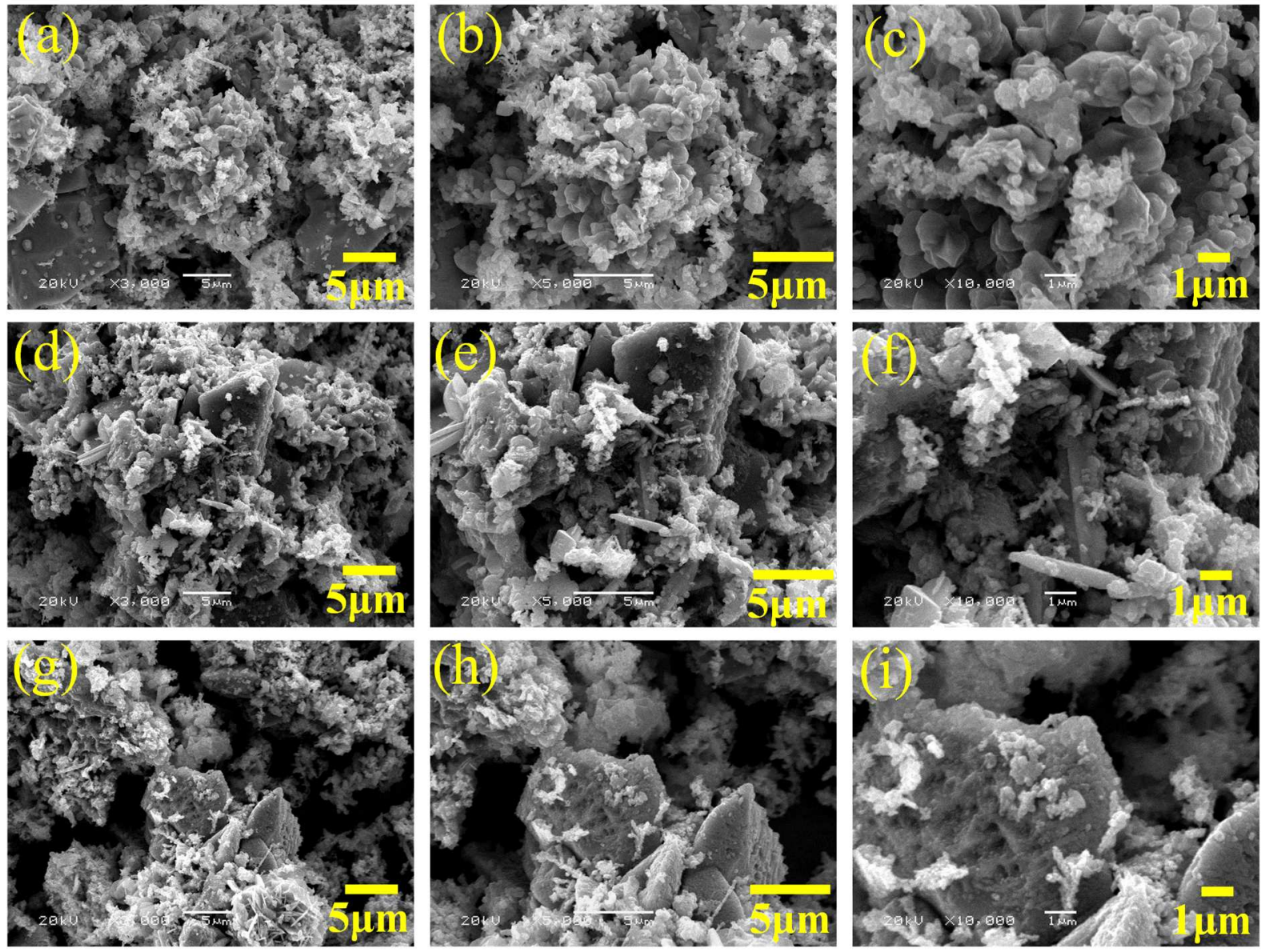

Fig. S2. The SEM images of the coatings after sand abrasion tests dropped from different heights: (a)-(c) 20 (d)-(f) 80 and (g)-(i) $100 \mathrm{~cm}$. For $h=20 \mathrm{~cm}$, the microstructures of the impinged surfaces changed little and the superamphiphobicity was maintained. When $h=80$ and $100 \mathrm{~cm}$, the impinged surfaces were covered with randomly scattered fragments of the damaged coatings. These surfaces maintain their superhydrophobic and highly oleophobic nature, however glycerol or peanut-oil can easily be "stuck" within the very rough microstructure. 


\section{Video S1}

The video shows that water, glycerol and peanut-oil droplets spread onto the as-received Al substrates, exhibiting hydrophilicity and lipophilicity, while these liquid droplets can easily roll off from the coated surface (the coating was bonded by double sided tape), showing excellent superhydrophobicity and superoleophobicity.

\section{Video S2}

The video shows that water, glycerol and peanut-oil droplets wet the uncoated glass slide substrates, exhibiting hydrophilicity and lipophilicity, while these droplets cannot wet the coated surface (the coating was bonded by double sided tape), indicating the coated surface has water/oil proofing properties.

\section{Video S3}

The video shows a sand abrasion test on a spray adhesive bonded superamphiphobic glass substrate. $150 \mathrm{~g}$ sand grains (300 to $800 \mu \mathrm{m}$ in diameter) fall from a height of $50 \mathrm{~cm}$ with a velocity of $3.2 \mathrm{~m} / \mathrm{s}$ just before impinging the surface. After the sand-blast treatment, the deposited water, glycerol or peanut-oil drops easily roll off the surface, demonstrating that the surface retains superamphiphobicity.

\section{Video S4}

Water, glycerol and peanut-oil droplet repellency test on the coated sponge substrate (the coating was bonded by spray adhesives).

\section{Video S5}

Water, glycerol and peanut-oil dropped on both uncoated and coated filter paper. The left part is uncoated while the right is coated (the coating was bonded by spray adhesives).

\section{Video $\mathbf{S 6}$}

Water, glycerol and peanut-oil repellence tests on a coated rubber ( $\sim \mathrm{cm}$ in length). These droplets readily roll-off from the coated rubber, even it is stretched to twice of its original length. The coated rubber maintains its superamphiphobicity after more than 50 stretch/release cycles. 